\title{
COMPARISON OF EMOTIONAL STATUS AND QUALITY OF LIFE IN WOMEN WITH DIFFERENT PHYSICAL ACTIVITY LEVELS DURING COVID-19 PANDEMIC
}

\section{Buse Ozcan Kahraman ${ }^{1}$, Karya Polat ${ }^{2}$, Gulbin Ergin ${ }^{3}$, Didem Karadibak ${ }^{1}$, Sema Savci ${ }^{1}$}

${ }^{1}$ Dokuz Eylul University, School of Physical Therapy and Rehabilitation, Izmir, Turkey
${ }^{2}$ Dokuz Eylul University, Graduate School of Health Sciences, School of Physical Therapy and Rehabilitation, Izmir, Turkey
${ }^{3}$ Izmir Bakircay University, Faculty of Health Sciences, Department of Physical Therapy and Rehabilitation, Izmir, Turkey

Address for Correspondence: Buse Ozcan Kahraman, PhD, E-mail: buse.ozcan@deu.edu.tr

Received: 30.01.2021; Accepted: 25.03.2021; Available Online Date: 27.05.2021

(C) Copyright 2021 by Dokuz Eylül University, Institute of Health Sciences - Available online at https://dergipark.org.tr/en/pub/jbachs

Cite this article as: Ozcan Kahraman B, Polat K, Ergin G, Karadibak D, Savci S. Comparison of emotional status and quality of life in women with different physical activity levels during COVID-19 pandemic. J Basic Clin Health Sci 2021; 2 : 15-21.

\begin{abstract}
Purpose: It was aimed to compare the effects of the coronavirus disease 19 (COVID-19) pandemic process on physically active and inactive women under general quarantine conditions. And second aim was to compare physical activity and general well-being in women who were employees and non-employees in a non-governmental organization.

Methods: A total of 286 women were included in this study. The research was conducted online via the Google Forms web survey platform. The demographic information of the participants and non-governmental organization volunteering were asked before the questionnaires. Individuals' levels of physical activity were assessed by International Physical Activity Questionnaire-Short form (IPAQ), stress level was assessed The Distress Thermometer index, anxiety levels were assessed with Generalized Anxiety Disorder-7 (GAD-7), quality of life was evaluated with the World Health Organization Quality of Life-Bref questionnaire (WHOQOL-Bref).
\end{abstract}

Results: It was found that physically inactive women had significantly higher anxiety and stress levels and lower quality of life $(p<0.05)$. And women who were employees in a non-governmental organization had significantly higher physically activity level and lower anxiety and stress levels and better quality of life $(p<0.05)$.

Conclusion: Physical activity has an intensely positive effect on anxiety, stress, and quality of life during COVID-19 pandemic under general quarantine conditions.

Keywords: COVID-19, physical activity, non-governmental organization, emotional status

\section{INTRODUCTION}

The coronavirus disease 19 (COVID-19) is a pandemic crisis that identified in December 2019 and then it spread throughout the world. To limit the spread of the disease, self-isolation (stay at home) was ordered from the governments to people and several restrictions started in Turkey such as flexible working from home, limiting physical proximity, closing schools, and move to learning from home, meet online, and citizens over 65 and under 20 are prohibited from going out (1).

Prolonged stays at home and the stressful situation because of the pandemic may cause a lifestyle behavior change such as physical activity (PA), emotional status, mental health, quality of sleep (24). Although the World Health Organization recommended to stay active at home, during the COVID-19 confinement decreased PA and increased 
daily sitting time has been reported in the recent studies (5-7). Total PA level was also showed lower in women compared to the men during COVID-19 pandemic (8).

It was shown that during the confinement period PA levels and perceived quality of life is associated with each other in general population $(9,10)$. In addition, it improves psychological health through the positive effect of PA on resilience to stress and reducing anxiety (11). It was demonstrated that continue regular PA is an important strategy to prevent mental and physical health during the COVID-19 pandemic. Generally it was stated that women burden, domestic work and unpaid care work at homes and communities increased during the pandemic and lockdown (12).

Considering the current studies, although it is seen that the quality of life has decreased and anxiety has increased because of the pandemic and the constraints that come with it in the general population, results on the only female population are insufficient. Considering that women can spare less time for themselves due to the increasing burden on women, the effects of physical activity, which is stated to be important during the pandemic period, on women should be emphasized. In this study, it was aimed to compare the effects of the COVID-19 pandemic process on physically active and inactive women under general quarantine conditions. And second aim was to compare physical activity and general wellbeing in women who were employees in a civil society organization and non-employees.

\section{METHODS}

This research is a cross-sectional study conducted with women 18 years and older living in Turkey during the COVID-19 pandemic between SeptemberDecember 2020. The research was conducted online via the Google Forms web survey platform. Participants were reached via social media (Facebook, WhatsApp) and e-mail. Before starting the survey, an explanatory text was added before the questionnaires to inform the participants about the study and informed consent was obtained from each participant. Ethics approval of this study is obtained from the Dokuz Eylul University Non-Invasive Research Ethics Board committee and the research is conducted in accordance with Helsinki Declaration (Decision no: 2020/21-31).

\section{Participants}

Two hundred and eighty-six women (mean age $=44.24 \pm 15.97$ years) from different social classes (married individuals $=63.3 \%$ ) and education levels (university graduates $=60.8 \%$ ), and voluntary to participate who were 18 years older and above and who can use a smart phone or computer participated the study. Participants were excluded if they had neurological diseases or limitations that could interfere physical activity or did not understand Turkish.

\section{Questionnaires}

The demographic information of the participants, their work situation during the COVID-19 period, the time spent outside the home, the level of anxiety about the pandemic and whether they were operating with the non-governmental organization were asked before the questionnaires.

\section{International Physical Activity Questionnaire - Short Form (IPAQ)}

Individuals' physical activity levels were evaluated by IPAQ. This questionnaire questions the physical activities performed in the past seven days and gives data about the time spent in sitting, and activities. The sitting score was calculated as daily sitting time separately. The short form total score calculation includes the sum of minutes and days of moderate and vigorous activity, and walking. The walking minutes is multiplied by $3.3 \mathrm{MET}$ in the calculation of the walking score. $4 \mathrm{MET}$ value was taken for the calculation of moderate activity and 8 MET value was taken for the calculation of vigorous activity. Classification for the physical activity levels were as $<600 \mathrm{MET}-\mathrm{min} /$ week = physically inactive, $600-3000$ MET-min / week = low physical activity, and $>3000$ MET-min / week = adequate physical activity (13).

\section{The Distress Thermometer index}

This index is a single-item, 10-point visual analogue scale. Responders indicate how distressed they have felt over the past week. Index was changed from "No Distress" to "Extreme Distress" (14).

\section{Generalized anxiety disorder-7 (GAD-7) Scale}

Individuals' anxiety levels were evaluated with GAD7. This questionnaire is a four-point Likert $0,1,2$, 3and 4 indicates none, many days, more than half of 
the days, and almost every day, respectively, paperpencil type scale that questions the last two weeks. The GAD total score is calculated by adding the scores from each question. The total scores obtained from the scale are 5 cut-off points for mild, 10 points cut-off for moderate, and 15 points cut-off for severe anxiety (15).

\begin{tabular}{|c|c|c|c|}
\hline Variables & $\begin{array}{l}\text { Total Sample } \\
\text { (n) \% }\end{array}$ & $\begin{array}{c}\text { Inactive } \\
\text { (n) \% }\end{array}$ & $\begin{array}{l}\text { Active } \\
\text { (n) \% }\end{array}$ \\
\hline \multicolumn{4}{|l|}{ Marital status } \\
\hline Single & (105) 36.7 & (63) 37.1 & (42) 36.2 \\
\hline Married & (181) 63.3 & (107) 62.9 & (74) 63.8 \\
\hline \multicolumn{4}{|l|}{ Education } \\
\hline High school & (38) 14.3 & (28) 16.5 & (10) 8.7 \\
\hline University & (174) 60.8 & (101) 59.4 & (73) 63.0 \\
\hline Master's degree & (49) 17.1 & (26) 15.3 & (23) 19.8 \\
\hline Doctoral degree & (25) 8.7 & (15) 8.8 & (10) 8.6 \\
\hline \multicolumn{4}{|l|}{ Employment } \\
\hline Public sector & (150) 52.3 & (94) 55.2 & (56) 48.4 \\
\hline Private sector & (84) 29.6 & (45) 26.5 & (39) 33.6 \\
\hline Student & (14) 4.9 & (9) 5.3 & (5) 4.3 \\
\hline Housewife & (15) 5.2 & (11) 6.5 & (4) 3.4 \\
\hline Retired & (23) 8.0 & (11) 6.5 & (12) 10.3 \\
\hline \multicolumn{4}{|l|}{ Chronic diseases } \\
\hline No & (199) 69.6 & (116) 68.2 & (83) 71.6 \\
\hline Yes & (87) 30.4 & (54) 31.8 & (33) 28.4 \\
\hline Asthma & (9) 3.1 & (7) 4.1 & (2) 1.7 \\
\hline COPD & (3) 1.0 & (3) 1.8 & NA \\
\hline Hypertension & (26) 9.1 & (15) 8.8 & (11) 9.5 \\
\hline $\begin{array}{l}\text { Cardiovascular } \\
\text { disease }\end{array}$ & (6) 2.1 & (2) 1.2 & (4) 3.4 \\
\hline $\begin{array}{l}\text { Thyroid related } \\
\text { disease }\end{array}$ & (20) 7.0 & (9) 5.3 & (11) 9.5 \\
\hline Diabetes Mellitus & (11) 3.8 & (7) 4.1 & (4) 3.4 \\
\hline $\begin{array}{l}\text { Polycystic over } \\
\text { syndrome } \\
\end{array}$ & (3) 1.0 & (3) 1.8 & NA \\
\hline $\begin{array}{l}\text { Rheumatologic } \\
\text { disease }\end{array}$ & (7) 2.4 & (6) 3.5 & (1) 0.9 \\
\hline Migraine & (2) 0.7 & (2) 1.2 & NA \\
\hline
\end{tabular}

\section{WHOQOL-Bref}

WHOQOL-Bref questionnaire measures the wellbeing of the person, and assess individuals' the quality of life, and World Health Organization (WHO) was developed this questionnaire. This questionnaire examines general health status, physical health, psychological health, social relations, and environmental health in 5 sub-parameters with 27 questions. The first question asks how the individual evaluates the quality of life and the second question asks how satisfied they are with their health. The questions are answered considering the last 15 days, and the higher the scores in the sub-parameters of physical health, psychological health, social relations and environmental health, calculated over 0-20 points, the higher the quality of life (16).

\section{Statistical Analysis}

The statistical analysis was conducted using the IBM SPSS software (Version 25.0, IBM Corp., Armonk, NY). Nonparametric analyses were used because the data were not normally distributed, as determined by Shapiro-Wilk test and histograms. Percentage (\%) and mean \pm standard deviation values were given in descriptive statistics. To compare the two groups in the continuous variables the Mann-Whitney $U$ test was used, and to compare the categorical variables chi-square test was used (17). Statistical significance was defined at $p<0.05$. The study's post hoc power analysis was calculated using the G-Power software (Version 3.1.9.7, Düsseldorf University, Düsseldorf, Germany) using the WHOQoL general health score effect size, the primary outcome measure.

\section{RESULTS}

Two hundred and eighty-six women were included to the two groups. The mean age of this study was 44.24 \pm 15.97 years and $63.3 \%$ of the individuals are married, $60.8 \%$ are university graduates, $52.3 \%$ are public sector employees and $69.6 \%$ do not have any chronic disease. The demographic information of the individuals included in this study is given in Table 1. The emotional status, IPAQ levels, sitting time during the day and quality of life of parameters of our participants were demonstrated in Table 2. The participants were divided to inactive (below 600 MET$\mathrm{min} /$ week) $(\mathrm{n}=170)$ women and active (600 MET$\mathrm{min} /$ week and over) $(\mathrm{n}=116)$ women.

There was no statistically significant difference in terms of chronic disease $(p=0.602)$, age $(p=0.172)$ and quality of life social domain score $(p=0.388)$ in both groups. The Anxiety $(p=0.002)$ and stress $(p=0.006)$ levels were statistically significantly higher in the physically inactive group compared to the active group. There were significant differences the sub-parameters of quality of life, physical score $(p<0.001)$, psychological score $(p<0.001)$, environmental area $(p=0.010)$ and the general health 
score $(p<0.001)$ in the physically active group compared to the inactive group (Table 2). The post hoc power of the study, which was calculated based on the effect size of the primary outcome measure was found as $86.0 \%$. non-governmental organization were more physically active and had lower anxiety and stress levels and better quality of life. Also, this study reflected the prevalence of physical activity in a small sample of women.

\begin{tabular}{|c|c|c|c|c|c|c|c|c|}
\hline \multirow{2}{*}{ Variables } & \multicolumn{2}{|c|}{ Total Sample $(\mathrm{n}=\mathbf{2 8 6})$} & \multicolumn{2}{|c|}{ Inactive $(n=170)$} & \multicolumn{2}{|l|}{ Active (n=116) } & \multirow{2}{*}{$\mathbf{z}$} & \multirow{2}{*}{ P value } \\
\hline & Mean \pm SD & Min-Max & Mean \pm SD & Min-Max & Mean \pm SD & Min-Max & & \\
\hline Age (year) & $44.24 \pm 15.97$ & $18-83$ & $43.05 \pm 15.65$ & $18.0-83.0$ & $45.99 \pm 16.35$ & $19.0-78.0$ & -1.367 & 0.172 \\
\hline $\begin{array}{l}\text { IPAQ-SF (MET- } \\
\mathrm{min} / \text { week) }\end{array}$ & $627.55 \pm 945.22$ & $0-6720.0$ & $135.76 \pm 200.19$ & $0-560.0$ & $1348.27 \pm 1128.63$ & $600.0-6720.0$ & -14.821 & $<0.001^{*}$ \\
\hline Daily sitting time (h) & $7.12 \pm 3.62$ & $1-19.0$ & $7.52 \pm 3.93$ & $1.0-19.0$ & $6.53 \pm 3.04$ & $2.0-18.0$ & -2.193 & $0.028^{*}$ \\
\hline GAD-7 (0-21) & $6.52 \pm 5.33$ & $0-21.0$ & $7.22 \pm 5.28$ & $0-20.0$ & $5.48 \pm 5.26$ & $0-21.0$ & -3.104 & $0.002 *$ \\
\hline $\begin{array}{l}\text { Distress Thermometer } \\
\text { score }(0-10)\end{array}$ & $5.31 \pm 2.76$ & $0-10.0$ & $5.67 \pm 2.63$ & $0-10.0$ & $4.77 \pm 2.85$ & $0-10.0$ & -2.733 & $0.006^{*}$ \\
\hline $\begin{array}{l}\text { WHOQoL physical } \\
\text { domain score }\end{array}$ & $28.53 \pm 3.99$ & $16.0-35.0$ & $27.77 \pm 4.22$ & $16.0-35.0$ & $29.66 \pm 3.32$ & $20.0-35.0$ & -3.703 & $<0.001^{*}$ \\
\hline $\begin{array}{l}\text { WHOQoL psychological } \\
\text { domain score }\end{array}$ & $22.29 \pm 3.95$ & $8.0-29.0$ & $21.51 \pm 4.07$ & $8.0-29.0$ & $23.42 \pm 3.48$ & $14.0-29.0$ & -4.236 & $<0.001^{*}$ \\
\hline $\begin{array}{l}\text { WHOQoL social domain } \\
\text { score }\end{array}$ & $11.16 \pm 2.18$ & $4.0-15.0$ & $11.08 \pm 2.15$ & $6.0-15.0$ & $11.28 \pm 2.22$ & $4.0-15.0$ & -0.863 & 0.388 \\
\hline $\begin{array}{l}\text { WHOQoL } \\
\text { environmental domain } \\
\text { score }\end{array}$ & $30.66 \pm 5.06$ & $15.0-40.0$ & $30.12 \pm 5.01$ & $15.0-40.0$ & $31.45 \pm 5.03$ & $15.0-40.0$ & -2.559 & $0.010^{*}$ \\
\hline $\begin{array}{l}\text { WHOQoL general health } \\
\text { score }\end{array}$ & $7.03 \pm 1.30$ & $4.0-10.0$ & $6.75 \pm 1.34$ & $4.0-10.0$ & $7.43 \pm 1.15$ & $4.0-10.0$ & -4.200 & $<0.001^{*}$ \\
\hline
\end{tabular}

The participants are divided into two groups according to whether they are volunteers in the nongovernmental organization (NGO) $(n=148)$ or not (Non-NGO) ( $n=138)$. Non-NGO volunteers' anxiety $(p<0.001)$, stress $(p<0.001)$ levels and daily sitting times $(p<0.001)$ were statistically significantly higher than NGO volunteers, and their physical activity level $(p=0.008)$, quality of life sub-parameters physical score $(p<0.001)$, psychological score $(p<0.001)$, social score $(p=0.001)$, environmental area $(p<0.001)$ and general health score $(p=0.001)$ in individuals who are non-governmental organization volunteers were lower (Table 3).

\section{DISCUSSION}

Daily regular exercise may help conflict the disease by improve human immune systems and counteracting some of the co-morbidities such as obesity, serious heart conditions, hypertension, and diabetes that make us more suitable to severe COVID-19 disease. Therefore, this study explored the effects of the COVID-19 pandemic process on physically active and inactive women under general quarantine conditions in Turkey. This study includes two major findings. First, physically inactive women had higher anxiety and stress levels and lower quality of life. Secondly, women who were employees in a
Females has shown $6-10 \%$ less physically active than males when the level of PA has been measured and activity level identified as, without considering measurement tool, protocol or definition (18). Also, female have increased rates of anxiety disorders prevalence, but gender effects on age of onset, burden of illness, comorbidity, and chronicity is less known. (19). For this reason, women were only evaluated in this study.

The global spread of the virus led in many countries, as in Turkey Government to implement extraordinary suppression procedures (20). Firstly, quarantine and then semi-lockdown times have disturbed the regularity of daily life, driving individuals to self and social isolation. The protective procedures have also involved sport-related activities, as well as running outdoors, and walking. Hence, home training persisted the merely opportunity to perform sports and keep on active during COVID-19 pandemic. In this work, we calculated the total MET-min/week and sitting time, after that analyzed and compared the anxiety, stress, and quality of life of 286 women, of which 170 was classified as in-active group.

Physical activity plays a fundamental role in the prevention of most chronic diseases. Unfortunately, based on the isolation at home and social distancing, the pandemic situation in COVID-19 serves a huge 


\begin{tabular}{|c|c|c|c|c|c|c|}
\hline \multirow{2}{*}{ Variables } & \multicolumn{2}{|c|}{$\begin{array}{l}\text { Employees in Non-Governmental } \\
\text { organizations }(n=148)\end{array}$} & \multicolumn{2}{|c|}{$\begin{array}{l}\text { Non-employees in Non-Governmental } \\
\text { organizations }(n=138)\end{array}$} & \multirow{2}{*}{$\mathbf{z}$} & \multirow{2}{*}{$P$ value } \\
\hline & $\operatorname{Mean} \pm$ SD & Min-Max & Mean \pm SD & Min-Max & & \\
\hline Age (year) & $56.18 \pm 9.78$ & $31.0-83.0$ & $31.44 \pm 10.46$ & $18.0-62.0$ & -12.741 & $<0.001 *$ \\
\hline IPAQ-SF (MET-min/week) & $761.75 \pm 1125.74$ & $0-6720.0$ & $483.62 \pm 677.12$ & $0-3360.0$ & -2.652 & $0.008^{*}$ \\
\hline Daily sitting time (h) & $5.87 \pm 3.01$ & $1.0-19.0$ & $8.46 \pm 3.75$ & $2.0-19.0$ & -6.839 & $<0.001 *$ \\
\hline GAD-7 (0-21) & $4.23 \pm 3.94$ & $0-19.0$ & $8.97 \pm 5.54$ & $0-21.0$ & -7.379 & $<0.001 *$ \\
\hline Distress Thermometer score (0-10) & $4.69 \pm 2.67$ & $0-10.0$ & $5.97 \pm 2.70$ & $0-10.0$ & -4.022 & $<0.001^{*}$ \\
\hline WHOQoL physical domain score & $29.58 \pm 3.85$ & $16.0-35.0$ & $27.42 \pm 3.83$ & $16.0-35.0$ & -4.772 & $<0.001 *$ \\
\hline WHOQoL psychological domain score & $24.0 \pm 3.25$ & $8.0-29.0$ & $20.44 \pm 3.81$ & $11.0-29.0$ & -7.794 & $<0.001 *$ \\
\hline WHOQoL social domain score & $11.58 \pm 1.87$ & $6.0-15.0$ & $10.72 \pm 2.40$ & $4.0-15.0$ & -3.360 & $0.001 *$ \\
\hline WHOQoL environmental domain score & $32.94 \pm 4.0$ & $19.0-40.0$ & $28.21 \pm 4.93$ & $15.0-38.0$ & -8.112 & $<0.001 *$ \\
\hline WHOQoL general health score & $7.26 \pm 1.34$ & $4.0-10.0$ & $6.78 \pm 1.22$ & $4.0-10.0$ & -3.472 & $0.001 *$ \\
\hline
\end{tabular}

effect on health, which may cause lifestyle changes such as insufficiency physical activity with economic and social consequences. Thus, in many studies, it was stated that due to the COVID-19 pandemic, more staying at home and imperative lifestyle changes reduce the physical activity level of individuals (21). Also, they showed decreases of quality of life and increases of depression in times of COVID-19 as compared to before COVID-19. In this study, we determined that the quality of life and emotional status in the group with high activity level was found to be better in comparison with that of the inactive group.

The literature shows that increasing levels of physical activity in healthy individuals do not lead to a decrease in sedentary behaviors such as less sitting time (22). For this reason, it is essential to reduce the time spent in sedentary behavior in addition to proposing increasing physical activity levels for maintaining health. In current study, it was determined that woman with better physical activity levels during the pandemic period also had shorter sitting periods. At the same time, the physical activity levels and sitting time of those working in nongovernmental organizations are positively affected. Non-governmental organizations have become more functional with constantly growing in importance and enlarging their sphere of influence both in Turkey and the worldwide. Non-governmental organizations play an important role in improving communities, developing society, and promoting citizen participation. In literature, it has been shown that nongovernmental organizations operate to improve their beneficiaries' quality of life aspects. But there is no study on the quality of life and activity levels of volunteer employees in non-governmental organizations. To the best of our knowledge, this is the first study which has shown the effect of volunteer work in non-governmental organizations on PA level, emotional status, and quality of life. So, we showed that the level of PA, emotional status, and the quality of life in the women with working in the NGO were found to be better in comparison with that of the noworking.

Meyer et al. indicated substantial decreases of PA and rises in inactive time through the universe and mainly along with previously physically active and self-isolated/quarantined individuals (23). Maugeri et al. demonstrated also a strong decline of PA levels, particularly for walking and vigorous activity (11). It revealed the main difficulties to do an intense exercise and walk at home, matched to moderate activity. And this situation may explain, in current study, why the mean MET values below 3000 MET$\mathrm{min} / \mathrm{wk}$ even in the active group. In the case of decreasing PA levels, it is important to ensure physical activity behaviors during pandemic. Cheval et. al. observed proof that increasing PA during leisure time was related with better physical and mental health (20). In current study, we showed that women were employees in a non-governmental organization, were more PA and had better physical, physiological, environmental, and social well-being in quality of life in accordance with the other studies $(20,24,25)$.

Regular exercise demonstrate less anxiety levels and depression and, thus strengthening the hypothesis that physical activity presents a useful impact next to 
the advancement of mental conditions (26). Numerous researches have proven that the effects of regular exercise to reduce anxiety are related to mediation of the endogenous opioid system and, alter in hypothalamic-pituitary-adrenal axis which are implicated in anxiety, emotional reactions, mood, and stress reactivity $(11,27)$. Moreover, physical activity is involved in the adjustment of Brain-derived neurotrophic factor (BDNF) which is one of these factors whose levels are regulated after exercise, signifies the most plentiful neurotrophin, that positively effects both depressive and anxiety disorders (28). Maugeri et al. showed that the relationship between the psychological well-being and decline of physical activity is greater in the women during COVID-19 pandemic. It has been also indicated that ordinary PA could be a way of encouraging resilience to stress in healthy adults (29). Carriedo et al. examined older adults of Spanish population during quarantine due to the COVID-19 pandemic and indicated that resilience was superior with physically active participants meeting the WHO's recommendations (24). Meyer et al. examined US adults during COVID-19 pandemic and determined a connection between sitting time, physical inactivity and anxiety (23). Lopez-Bueno et. al. studied in a large section of the Spanish universe found that to accomplish a minimum 150 weekly minutes of PA was considerably related with lesser probabilities for feeling elevated perceived anxiety while COVID-19 detention (30). The current study also showed active women had lower anxiety and stress levels and better physiological level supported by previous studies.

Studies have mostly revealed gender variations in physical activity behaviors and motivations $(31,32)$. Men perform physical activity primarily for communal and competitive purposes. Furthermore, men wish to put into sports, in public areas like the fitness clubs and gym and/or outdoor. Women are more prone to exercise such as practicing aerobics, Pilates, yoga, squats, dancing, planks and jumping jacks in homesetting. Moreover, Grazia et al. explained the lower difference in levels of physical activity between before and during quarantine found in women were probably due to the higher amount of housekeeping physical activity than males (11). Herewith conducted on women population was strength of this study. Therefore, other limitations were that there was no time to authenticate the scales and measures for their usage with women in an online system. And not knowing previous physical activity levels and not being able to analyze according to change were among our limitations.

In conclusion, based on the $\mathrm{WHO}$, viral diseases represent a serious issue to public health and continue to emerge. So, the uncertainty about viral diseases increases the anxiety level of the society. PA has an intensely positive effect on anxiety, stress, and quality of life during COVID-19 pandemic under general quarantine conditions in women. Therefore, specific suggestions to focus on home-based training during this time are extremely required for women.

Conflict of Interest: No conflict of interest was declared by the authors.

Financial Disclosure: The authors declared that this study has received no financial support.

Peer-review: Externally peer-reviewed.

\section{REFERENCES}

1. T.C. İçişleri Bakanlığı. Haberler - Genelgeler, https://www.icisleri.gov.tr/haberler-yeni.

2. Jiménez-Pavón D, Carbonell-Baeza A, Lavie CJ. Physical exercise as therapy to fight against the mental and physical consequences of COVID-19 quarantine: Special focus in older people. Prog Cardiovasc Dis. 2020; 63: 386-388.

3. Hall G, Laddu DR, Phillips SA, et al. A tale of two pandemics: How will COVID-19 and global trends in physical inactivity and sedentary behavior affect one another?. Prog Cardiovasc Dis. 2021; 64: 108-110.

4. Maugeri G, Castrogiovanni P, Battaglia G, et al. The impact of physical activity on psychological health during Covid-19 pandemic in Italy. Heliyon. 2020; 6: e04315.

5. Ammar A, Brach M, Trabelsi K, et al. Effects of COVID-19 Home confinement on eating behaviour and physical activity: Results of the ECLB-COVID19 International online survey. Nutrients. 2020; 12: 158.

6. Castañeda-Babarro A, Arbillaga-Etxarri A, Gutiérrez-Santamaría B, et al. Physical activity change during COVID-19 confinement. Int J Environ Res Public Health. 2020; 17: 6878.

7. Stay physically active during self-quarantine, https://www.euro.who.int/en/health-topics/healthemergencies/coronavirus-covid-19/publicationsand-technical-guidance/stay-physically-activeduring-self-quarantine (accessed 10 January 2021).

8. Tural E. Covıd-19 pandemi dönemi ev karantinasında fiziksel aktivite düzeyinin yaşam kalitesine etkisi. Van Sağ Bil Derg. 2020; 13: 10_ 18.

9. Slimani M, Paravlic A, Mbarek F, et al. The relationship between physical activity and quality 
of life during the confinement induced by COVID19 outbreak: A pilot study in Tunisia. Front Psychol. 2020; 11: 1882.

10. Tunç AÇ, Zorba E, Çingöz YE. Covid 19 Salgını döneminde egzersizin yaşam kalitesine etkisi. Uluslararası Güncel Eğitim Araştırmaları Dergisi. 2020; 6: 127-135.

11. Maugeri G, Castrogiovanni $P$, Battaglia G, et al. The impact of physical activity on psychological health during Covid-19 pandemic in Italy. Heliyon. 2020; 6: e04315.

12. Power K. The COVID-19 pandemic has increased the care burden of women and families. Sustainability: Science, Practice and Policy. 2020; 16: 67-73.

13. Saglam M, Arikan H, Savci S, et al. International physical activity questionnaire: reliability and validity of the Turkish version. Percept Mot Skills. 2010; 111: 278-284.

14. Roth AJ, Kornblith AB, Batel-Copel L, et al. Rapid screening for psychologic distress in men with prostate carcinoma: a pilot study. Cancer. 1998; 82: 1904-1908.

15. Spitzer RL, Kroenke K, Williams JBW, et al. A brief measure for assessing generalized anxiety disorder: the GAD-7. Arch Intern Med. 2006; 166: 1092-1097.

16. Development of the World Health Organization WHOQOL-BREF quality of life assessment. The WHOQOL Group. Psychol Med. 1998; 28: 551558.

17. Murat Hayran, Mutlu Hayran. Sağlık Araştırmaları İçin Temel İstatistik. Ankara: Art Ofset Matbaacılık Yayıncılık Organizasyon Ltd. Şti., 2011.

18. Hands B, Parker H, Larkin D, et al. Male and female differences in health benefits derived from physical activity: Implications for exercise prescription. J Womens Health, Issues and Care. 2016; 5: 4.

19. McLean CP, Asnaani A, Litz BT, et al. Gender differences in anxiety disorders: Prevalence, course of illness, comorbidity and burden of illness. J Psychiatr Res. 2011; 45: 1027-1035.

20. Cheval B, Sivaramakrishnan $H$, Maltagliati $S$, et al. Relationships between changes in selfreported physical activity, sedentary behaviour and health during the coronavirus (COVID-19) pandemic in France and Switzerland. J Sports Sci. 2020; 00: 1-6.

21. Di Renzo L, Gualtieri P, Pivari F, et al. Eating habits and lifestyle changes during COVID-19 lockdown: an Italian survey. J Transl Med. 2020; 18: 229.

22. Lu C, Chi X, Liang K, et al. Moving more and sitting less as healthy lifestyle behaviors are protective factors for Insomnia, depression, and anxiety among adolescents during the COVID-19 pandemic. Psychol Res Behav Manag. 2020; 13 : 1223-1233.

23. Meyer J, McDowell C, Lansing J, et al. Changes in Physical activity and sedentary behavior in response to COVID-19 and their associations with mental health in 3052 US adults. Int J Environ Res Public Health. 2020; 17: 6469.

24. Carriedo A, Cecchini JA, Fernandez-Rio J, et al. COVID-19, Psychological well-being and physical activity levels in older adults during the nationwide lockdown in Spain. The Am J Geriatr Psychiatry. 2020; 28: 1146-1155.

25. Antunes R, Frontini R, Amaro N, et al. Exploring lifestyle habits, physical activity, anxiety and basic psychological needs in a sample of Portuguese adults during COVID-19. Int $\mathrm{J}$ Environ Res Public Health. 2020; 17: 4360.

26. van Minnen A, Hendriks L, Olff M. When do trauma experts choose exposure therapy for PTSD patients? A controlled study of therapist and patient factors. Behav Res Ther. 2010; 48: 312-320.

27. Rimmele U, Costa B, Marti B, et al. Trained men show lower cortisol, heart rate and psychological responses to psychosocial stress compared with untrained men. Psychoneuroendocrinology. 2007; 32: 627-35.

28. Phillips C. Brain-Derived Neurotrophic factor, depression, and physical activity: making the neuroplastic connection. Neural Plast. 2017; 2017: 7260130.

29. Childs E, de Wit H. Regular exercise is associated with emotional resilience to acute stress in healthy adults. Front Physiol. 2014; 5: 161.

30. López-Bueno R, Calatayud J, Ezzatvar Y, et al. Association between current physical activity and current perceived anxiety and mood in the Initial phase of COVID-19 confinement. Front Psychiatry. 2020; 11: 729.

31. Tiggemann M, Williamson S. The Effect of Exercise on Body Satisfaction and Self-Esteem as a Function of Gender and Age. Sex Roles. 2000; 43: 119-127.

32. Lustyk MKB, Widman L, Paschane AAE, et al. Physical activity and quality of life: assessing the influence of activity frequency, intensity, volume, and motives. Behav Med. 2004; 30: 124-131. 